\title{
NUEVOS DATOS SOBRE LOS OFICIOS Y PUESTOS DE VELÁZQUEZ EN LA CASA REAL
}

Los oficios y puestos que disfrutó Velázquez, al servicio de Felipe IV, que como Palomino señalaba, le robaron tiempo para dedicarse a la pintura, pues «suspender el ejercicio de una habilidad, más es castigo que premio» ${ }^{1}$, han sido ya objeto de estudio, pero, a la luz de los documentos pertenecientes a la Mayordomía del Conde de Montalbán ${ }^{2}$, se pueden aclarar algunos datos.

Velázquez ocupó, desde su llegada a la Corte, diversos puestos en la Casa Real, Pintor de Cámara desde 1623, Ujier de Cámara desde $1627^{3}$, Ayuda de Guardarropa desde 1636, Ayuda de Cámara desde $1643^{4}$, en 1648 ya se le cita como uno de los superintendentes de las obras reales ${ }^{5}$, y ocupa el cargo de Aposentador Mayor desde 1652 hasta su muerte ${ }^{6}$. Sobre estas dos ocupaciones daremos alguna nueva noticia.

Sobre el cargo de Aposentador ${ }^{7}$, cuya concesión, señala en cuanta estima tenía el rey a Velázquez, pues era cargo de responsabilidad ${ }^{8}$, normalmente ocupado por personas de alta dignidad, sabemos que en 1652, Velázquez sucede a Pedro de Torres, y a su muerte en 1660 , le sucederá Don Francisco de Rojas y Contreras, «Secretario y Ayuda de Cámara de su Mágestad» ${ }^{9}$. A la muerte de Velázquez, será pues él quien tenga que hacerse cargo de todos los muebles y llaves de palacio, obligación que comporta dicho oficio de la furriera [Doc. Ia y Ib] en la casa real. Incluso tendrá que hacerse cargo de los objetos más insignificantes como unas sillas viejas, y siguiendo la terrible etiqueta de Palacio, para desembarazarse de ellas tendrá que dar cuenta primero al Mayordomo Mayor, quién, previo informe requerido al controlador, dará cuenta al Rey. No solamente podemos ver de nuevo en la documentación de la Mayordomía de Montalbán cuán complicada era la vida administrativa en Palacio, sino que también, se incide de nuevo en la conocida miseria en que vivían los criados del rey ${ }^{10}$.

Cuando muere Velázquez, dice Palomino, que las envidias «quisieron enturbiar su honradez al servicio del rey» ${ }^{11}$, e incluso contábamos ya con la documentación del ajuste de

1 Palomino, A.: El Museo Pictórico y escala óptica III: El Parnaso español pintoresco laureado. $1 .^{a}$ Ed. 1796. Ed. Consultada: Aguilar 1988, p. 246.

2 El Conde de Montalbán ocupaba en estos años el puesto de Mayordomo Mayor, que era el cargo de más alta dignidad. Véase: Deleito y Piñuela: El rey se divierte. (1. ${ }^{a}$ Ed. 1988) Ed. 1997, p. 109, en que sigue la crónica de Núñez de Castro, Sólo Madrid es Corte.

3 Palomino, A.: Op. cit., p. 273. Para éstos y los siguientes nombramientos: Varia Velazqueña. Vol. II. Madrid 1960, pp. 222 y ss.

4 Sobre estos dos cargos, véase El Arte de la pintura (1649), de Pacheco, en la Ed. de Cátedra de 1990, las indicaciones dadas por Bonaventura Bassegoda I Hugas, autor de dicha edición en las cuales aclara el por qué de las fechas erróneas que señala en el original Pacheco. Palomino, A.: Op. cit., p. 273: Da la fecha de 1642 para su nombramiento como Ayuda de Cámara.

5 Martín González, J. J.: El artista en la sociedad española del siglo XVII. Ed. Cátedra, 1984, p. 165.

6 Palomino, A.: Op. cit., p. 245.

7 Justi, C.: Velázquez y su siglo. Bonn 1888. Ed. Istmo Madrid 1999, pp. 542-574.

8 Pérez Sánchez, A. E.: Velázquez y su arte. En Catálogo de la exposición de Velázquez. Museo del Prado 1990 , p. 46.

Palomino, A.: Op. cit., p. 245: Aporta ambos nombres como predecesor y sucesor de Velázquez en el cargo de Aposentador. Martín González, J. J.: Op. cit., p. 167, señala que fue aposentador después de Velázquez José de Villareal.

10 Deleito y Piñuela: $O p$. cit., p. 108.

$"$ Palomino, A.: Op. cit., p. 271. 
cuentas que se hacen del gasto del oficio de la furriera después de su fallecimiento ${ }^{12}, \mathrm{y}$ con las noticias que tenemos ahora [Doc. II], me atrevo a indicar alguna conclusión: Quizá si se realizasen las cuentas por las causas que indica Palomino, pero también, como vemos en las cuentas del año 1665-1666, para ajustar el dinero que Velázquez había cobrado por dicho puesto y que debía repartir entre los del oficio de la furriera, y también para ver los salarios que se debían a Velázquez cuando murió. Justi ya habló de la «ligereza del español en cuestiones económicas», al tratar este asunto, pero no se produce un secuestro ${ }^{13}$ de los bienes, sino un embargo hasta que estén liquidadas las cuentas. De hecho, es Mazo quien quiere depositar los 17.957 reales, pero, y ahí radicaba el problema recibiendo a cambio «certificación de haber cumplido con su alcance», que no se conseguirá como es sabido hasta el Real Decreto de 17 de febrero de 1666, para que pudiese la herencia quedar libre del embargo al cual estaba sometida. Es lógico pensar que se debían liquidar las cuentas de cualquier cargo que comportase la distribución de dinero, considerando que si no se habían realizado, antes de su muerte, debían ajustarse antes de que recibiesen la herencia los herederos, siguiendo el principio, «nemo liberalis, nisi liberatus», por lo cual no necesariamente se realizarían estas cuentas por «envidias». Así, la documentáción que haga referencia a la tasación y herencia de los bienes de Velázquez, podría estar vinculada a la documentación administrativa de Palacio, entre febrero de 1666 y el mismo mes del año siguiente en que muere Mazo, tiempo en que él es curador de los bienes que han de heredar sus hijos, o incluso, en las fechas posteriores a su muerte al realizarse la liquidación de su herencia.

Sobre el cargo de Superintendente de obras reales, podemos aportar también algún nuevo dato [Doc. III]. Este cargo, que implicaba las tareas de inspección e información acerca de las obras reales ${ }^{14}$, al ser un cargo que supone a quien le es otorgado una cốnfianza del rey, es susceptible de tener nuevas atribuciones si, quien goza del puesto es un personaje como Velázquez, que con sus opiniones, aún no siendo arquitecto, puede contribuir a crear un determinado tipo de ambientes ${ }^{15}$. En esta nueva documentación nos aparece como un auténtico vigilante de las obras que se están realizando en Palacio, encargadas a Carbonell ${ }^{16}$, al cual previamente se le pidió tanteo para llevarlas a cabo. El Conde de Montalbán, en su puesto de Mayordomo Mayor, avisa al rey, del retraso en la fortificación del oratorio y guardajoyas que él había ordenado, y de cómo será Malpica, en quien recaían los cargos de mayordomo y superintendente ${ }^{17}$, como era usual ${ }^{18}$, quien se ocupe de arreglar el «agujero», del cual ha dado aviso Velázquez. Este cubo, perteneciente a la antigua fortaleza, está en la fachada que mira al Este ${ }^{19}$, sabríamos por tanto que «encima» ${ }^{20}$ es donde se sitúa la habita-

12 Varia Velazqueña, 1960. Doc. 223, pp. 406 a 410. Recogidos en parte por Zarco en Documentos inéditos, p. 428 y totalmente por Cruzada en Anales de la vida y de las obras de Diego de Silva y Velázquez. Madrid 1885, p. 206-224.

13 Justi, C.: Op. cit., p. 549.

14 Martín González, J. J.: Op. cit., p. 165.

15 Barbeito, J. M.: «Velázquez y las obras reales», en El Real Alcázar de Madrid, Madrid, 1994, p. 91: senala su contribución a la definición interior del espacio barroco.

16 Estas reformas que lleva a cabo Carbonell en Palacio, serán publicadas próximamente por J. L. Blanco Mozo que realiza la tesis doctoral: Alonso Carbonell, arquitecto del Conde-Duque de Olivares.

17 Martín Ortega, A.: Testamento de pintores. B.S.A.A., 1996, pp. 412-413.

18 Tovar, V.: Significación de Juan Bautista Crescencio en la arquitectura española del siglo XVII. A.E.A. n. ${ }^{\circ} 215,1981$, p. 297 .

${ }_{19}$ Barbeito, J. M.: El Alcázar de Madrid. Madrid 1992, pp. 127-129; 143-150. Para la situación de las estancias se ha seguido la numeración de los planos que incluye de Gómez de Mora. A mi parecer sería la zona señalada en la Planta baja con los n. ${ }^{o s} 118,119,42$ y 122 (oratorio, que sería el «relicario»).

20 Por tanto, en el cubo señalado con el n. ${ }^{\circ} 9$ en el plano de la Planta Principal de Gómez de Mora. 
ción donde trabajaba Carbonell, en la misma ala pero en el lado opuesto de las ocupadas por Velázquez ${ }^{21}$ y que en esta fecha de 1653 , se debía de encontrar en una disposición distinta a la que se ve en el plano de 1626 de Gómez de Mora ${ }^{22}$ ya que el relicario no tiene ninguna ventana «que cae al patio» y formarían también parte del guardajoyas las habitaciones que dan al mismo ${ }^{23}$.

Pero además de llevar a cabo esta labor de inspector, su cargo de Superintendente, traía consigo la tarea de participar en la decoración, como «orientador del gusto» de las distintas casas reales, como el Pardo, para donde toma del guardajoyas un farol, o del Escorial. Sobre la contribución decorativa de Velázquez en el Monasterio, tenemos diversas noticias ${ }^{24}$, siguiéndose normalmente, la memoria realizada según el escrito publicado en Roma en 1658, tomada como obra de Velázquez, aunque no incluya referencias a otras salas que no sean la sacristía, antesacristía y sala capitular, por lo cual, autores como Cruzada Villaamil, o Justi la juzgan falsa ${ }^{25}$.

Sobre los objetos que se llevan a la sacristia del Panteón, contábamos, aparte de la descripción del Padre Santos, con la noticia dada por Hernández Perera sobre el Cristo de Marfil llevado por Velázquez ${ }^{26}$. A través de la nueva documentación encontrada, se puede conocer mejor la fecha y los objetos llevados al panteón [Doc. IV y V]. Como ya intuyó Hernández Perera, la anotación marginal para descargarla al guardajoyas, que se hace en el inventario de 1653 que él vio en Palacio, es posterior como señalaba, pudo realizarse «acaso en 1654». Efectivamente, en dicho año es cuando se le indica a Velázquez que escoja del guardajoyas, aquello que quisiera, es decir se le da facultad por parte del rey para que a su gusto elija las pinturas y objetos que desee llevar, lo cual, viene a confirmar una vez más que la elección de Velázquez como aposentador, fue realizada en virtud de la confianza personal que en el gusto del Sevillano tenía ya depositada el monarca desde hacía tiempo: se deja a su elección la decoración de este otro ámbito del Monasterio, con lo cual no es de extrañar, que de las veinticinco pinturas que decoraban esta sacristía, según el padre Santos, la mayor parte o la totalidad, fuesen escogidas por Velázquez ${ }^{27}$.

21 Vivió en la torre dorada hasta que en 1655 se traslada a vivir a la Casa del Tesoro. Rosario Díez del Corral: «El entorno del Palacio», en El Real Alcázar de Madrid, 1994.

22 Tovar Martín, V.: Arquitectura Madrileña del siglo XVII. Madrid 1983, y en Cat. Exp. Juan Gómez, de Mora (1586-1648). Madrid 1986.

23 Corresponderían también al Guardajoyas además de los n. ${ }^{\text {ss }} 119$ y 121 la 42 a la cual corresponderían las «dos ventanas del guardajoias que caen al patio». Es probable que las habitaciones 37 a 41 ya no correspondiesen en este año a la Condesa de Lemos, sino que tendrían otra función. Justi, C.: Op. cit., recoge un plano del piso principal con las funciones que podrían desempeñar las habitaciones. No se recoge en la última edición.

${ }_{24}$ De Castro, A.: Noticia de Don Diego Velázquez y Silva como escritor ofrecida a la Real Academia Española por Don... Memorias de la Academia Española, T. III 1871, pp. 479-520. Morán Turina y Checa, F.: Las colecciones pictóricas del Escorial y el gusto Barroco. Goya n. ${ }^{\circ} 1984$, pp. 252 a 261 . El coleccionismo en España. Madrid, 1985, Pérez Sánchez, A. E.: Op. cit., 1990, p. 50. Francisco de los Santos: Descripción breve del Monasterio el Real del Escorial, 1657. Ed. Almiar Facsímil, 1984. A partir de la descripción del padre Santos, se sigue siempre la supuesta Memoria de Velázquez.

25 Cruzada Villaamil, G.: Op. cit., Cruzada además la considera apócrifa por no incluir alusiones a otras partes. Justi, C.: Op. cit., pp. 564-575.

${ }^{26}$ Hernández Perera, J.: Un Cristo de marfil llevado por Velázquez al panteón de El Escorial. A.E.A. n. $130-131,1960$, pp. 295-297. Extrae la noticia del Archivo General de Palacio.

27 Idea también señalada por Hernández Perera, op. cit., p. 297. De los Santos, F.: Op. cit., p. 141v a 143r: Decoración de la sacristía del Panteón. Fr. A. Jiménez: Descripción del Real Monasterio de San Lorenzo del Escorial. Madrid, 1764, p. 370. Sigue la obra de Santos. Ponz: Viaje de España. Ed. 1947, p. 175. Ya no incluye las pinturas, que serían retiradas. De Quevedo, J.: Historia del Real Monasterio de San Lorenzo del Escorial. Madrid, 1854. Ed. 1986, p. 300, tampoco habla de las pinturas. 
Las pinturas, que según esta documentación, elige Velázquez, son tres. Es curioso que en la misma partida todas sean tablas flamencas. Según la descripción del padre Santos, serán veinticinco pinturas las que decoren este recinto, que además de utilizarse para las funciones propias de una sacristía, puesto que la del templo quedaba alejada, también era la estancia donde debían permanecer las cajas exteriores de los cadáveres, trasladados al pudridero, pero que estaban destinados al panteón de infantes, hasta que pasados los oportunos 30 o 40 años se colocaban de nuevo en ellas las cajas de plomo y de allí, se trasladaban a su morada definitiva.

Sobre el tabernáculo, la descripción que incluye tasación, corresponde exactamente con la del Archivo de Palacio, aunque no incluya la caja. Las medidas dadas para el Cristo, «media vara» o «más de tercia» de alto, entre 0,415 y 0,276 de alto, se correspondería, a mi entender, con el Cristo de marfil llamado de Isabel Clara ${ }^{28}$, además Santos, ya indicaba un «Cristo vivo en la Cruz de famosísima inventiva».

Sobre las tablas flamencas, que se llevan al Panteón, la Adoración de los Reyes, la Anunciata, aparecen ya citadas por Santos como «Unas tablas de la adoración de los Reyes y otras dos del nacimiento y de la anunciación antiguas flamencas», que estarían situadas por las paredes «de este hueco» (se refiere al nicho donde está situado el Cristo), y la Virgen San Juan y la Magdalena, de la cual sí nos da medidas el documento $(0,6225 \mathrm{x}$ 0,415 aproximadamente), la sitúa el cronista «...últimamente al salir está un descendimiento de la cruz copia de Daniel». La anunciación y la adoración, hacen pensar en las puertas laterales del oratorio (inventario actual del Prado n. ${ }^{\circ} 1461$ ), que sabemos se trasladaron del Escorial al museo ${ }^{29}$, aunque la breve descripción del documento hace referencia

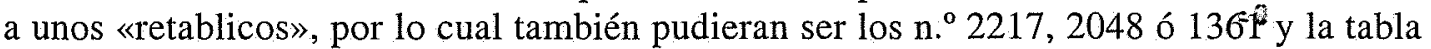
central de la Anunciación la de Campin, n. ${ }^{\circ}$ 1915, que también procede del Escorial. Respecto al descendimiento puede tratarse de alguna pequeña copia del de Volterra que se situó a la entrada de la Sacristía.

Se puede confirmar con estos datos que Velázquez participó en la decoración de todos los ámbitos del Escorial de una forma muy directa, ya que tuvo gran libertad en la elección de los objetos y pinturas que se llevan al monasterio. Todas estas obras que se llevan al Escorial van tasadas, ya que era un legado. Felipe IV, conmovido por el traslado de los cuerpos reales al Panteón, en 1554, según señala Santos, realiza diversas donaciones al Monasterio, como las de pinturas, contribuyendo así a enriquecer la colección pictórica del Escorial, a cuya decoración, como se reafirma con las noticias que se van encontrando, contribuyó Velázquez.

M. a JESÚS MUÑOZ GONZÁLEZ

${ }_{28}$ Estella Marcos, M.: La escultura Barroca de Marfil en Espã̃a. C.S.I.C. 1984, Vol. I, pp. 49-52; 64-66. Ya plantea la cuestión señalando que el n. ${ }^{\circ} 62$ del catálogo, conocido como Cristo de Isabel Clara, bien pudiera ser el Cristo del inventario de 1653, citado por Hernández Perera, aunque por estar en la situación original, parece responder al n. ${ }^{\circ} 1553$ del inventario del Escorial y las medidas de la cruz no corresponden, por lo que se habría debido amoldar posteriormente.

29 Polero, V.: Catálogo de pinturas del Real Monasterio del Escorial. Madrid 1857. 


\section{APÉNDICE DOCUMENTAL}

\section{DOCUMENTO Ia: ARCHIVO HISTÓRICO NACIONAL. SECCIÓN NOBLEZA. TOLEDO. FONDO FRIAS CAJA 224. VOLUMEN DE LOS AÑOS 1648-1655}

Fol 276r: Madrid Setiembre 20 1654. Remite papel de Juan Lorenzo de Quellar y gaspar de fuensalida en que dan q.ta ay algunas cosas viejas en la g.da joyas que embaraçan y no pueden servir, para que se repartan entre los oficiales della. Responde: Vea esto Velazquez, y lo que no fuere de provecho se aga lo que dicen./277r: A Juan Lorenzo de Cuellar y Gaspar de Fuensalida que estan tomando las quentas de la guardajoyas le a parecido lo contenido en ese papel yncluso que aviendole visto V. Mag.d se sirva hordenarme lo que se ha de hacer./278r: entre las cosas que estamos cargando Don Francisco Tamayo guardajoyas que sirven de data y satisfación para el cargo de Don Geronimo de Villafuerte se allan mucha cantidad de pinturas, mapas, lienzos, vastidores, maderas, marcos, arcas, y cofres, viejos inutiles y otras muchas cosas que no son de provecho que sirven mas de embaraço, y gastar el tiempo en haçer cargo dellas, nos a parecido dar quenta a V $S^{u}$, para quesela de a su Mag.d para que se vean por quienfuere servido y dando su Mag.d el descargo en la forma que se acostumbra se vajen del Cargo de Don Geronimo y se dan por consumido.

\section{DOCUMENTO Ib: ARCHIVO HISTÓRICO NACIONAL. SECCIÓN NOBLEZA. TOLEDO. FONDO FRIAS CAJA 229. VOLUMEN DEL AÑO 1660.}

Fol 245r: Haviendome dado quenta Dn Fran.co de Rozas de quentre las cosas q. Dejo Diego Velazquez. del oficio de la furriera, halló algunas sillas de todos generos rotas y comidas de ratones que no estavan de servicio, y solo servian de embaraço que seria bien que no se le hiciese cargo de ellas pues solo servian de embaraçar los aposentos y las tablas viejas y quebradas de los cajones yen que an traido alg.s cosas que seria bien que se echasen y repartiesen entre los varrenderos oficiales de la furriera que estan muy pobres, y se les debe mucho. Di orden al Contralor que lo reconociese, y me informase por escrito (como ha hecho) por el papel incluso, en que me pareze propone cosa justa D. Franc.o de Roxas, y dandome V. Mg. Licenzia se dará lo que dize Dn fra.co y a él por jefe del oficio se le dará lo que pareciere mas competente. Madrid. Nov.re 8 de 1660.

\section{DOCUMENTO II: ARCHIVO HISTÓRICO NACIONAL. SECCIÓN NOBLEZA. TOLEDO. FONDO FRIAS CAJA 229. VOLUMEN DEL AÑO 1665.}

Fol 103r: Juan Baptista del Mazo me ha representado, que está promto a pagar los diez y siette mil novecientos y cinquenta y siette reales, en que Diego Velazquez su suegro fue alcanzado en las quentas del tiempo, que sirvio el oficio de Aposentador de Palacio, entregando el dinero al Maestro de la Camara para que con intervencion del Contralor se satisfaga a las personas que lo han de haver en la conformidad que lo resolvio el rey mi señor a Consulta del Bureo de su real Casa; suplicandome mande que assi se execute. Y porque he venido en ello dareis la orden necessaria para que esta satisfaccion se fenezca en la forma resuelta, y en estando concluida se entregará certificación a Juán Bap.ta de haver cumplido con el alcance de dichas quentas para que quede libre el uso de los bienes a los herederos de Diego Velazquez./En Md. a 15 de Dic.e 1665.

\section{DOCUMENTO III: ARCHIVO HISTÓRICO NACIONAL. SECCIÓN NOBLEZA. TOLEDO. FONDO FRIAS CAJA 224. VOLUMEN DE LOS AÑOS 1648 A 1655.}

Fol 215r: Md oct 22 1653./Da quta. de un agugero que se allo en la torre que esta junto a la bobedilla del despacho y como no se acenada en la fortificación del g.da joyas y oratorio./Responde: e mandado se esecute luego lo que estava resuelto y lo que agora decis. $215 \mathrm{v}$ : Da quenta de un abujero que se a hallado en el cubillo que esta debajo de donde tíene carbonel sus papeles y como no se hace nada en la fortificácín del guardajoyas y oratorio y como lo más precísso es echar un larguero de yerro entre la pared y la reja del oratorio por caber un muchacho en el gueco que ay./216r: (he mandado se execute luego por lo que estava resuelto y lo que ahora decis)/Oy me dijo Diego Velazquez que avia visto en un cubillo de los que estan a la parte del parque un abujero que cabia una persona por el y que no sabia adonde caía, fuímos juntos y con una escalera hiçe que subiese un muchacho y entrasse por el abujero a reconocer a donde cae y lo que avia dentro, y si allo que no tenía puerta ni correspondencia a ninguna parte, arrima en medio de la guardajoias, y según parece es gueco condenado que cae debajo del cubillo donde tiene carbonel sus papeles./ Y aunque creo que el marques de malpica lo hara tapar luego por averle dado aviso dello Díego Velazquez, pero e entrado en cuydado del intento con que se hiço este abujero, y ser la pared gruessa que lo es mucho menos los cerramientos de las dos ventanas de la guardajoias 
que caen al patio, y que en la reja de la ventana del relicario que cae al patio por entre la solera y la pared cabe un muchacho como lo esperimentamos oi Diego Velazquez y yo para cuio remedio avia ordenado al zerrajero de V.M. g. echasse un larguero de yerro gruesso a la larga entre la solera y la pared, y como V.M.g cometi6 a el marques de Malpica por consulta mía cuidasse de las fortificaciones que tenía resueltas se hiciessen en la guardajoias y oratorio, no e tratado más de ello. veo que no se haçe y que es muy necesario y lo parece más después de haver (fol 116v). hallado la rotura deste abujero, y aunque yce poner cerraduras en la ventana del relicario, tengo por mas precisso, el assegurar aquella reja, de que doi quenta a v.mg. para que se sirva de ordenar con brevedad se remedie este peligro. Md octubre 22 de 1653.

\section{DOCUMENTO IV: ARCHIVO HISTÓRICO NACIONAL. SECCIÓN NOBLEZA. TOLEDO. FONDO FRIAS CAJA 223. VOLUMEN DE LOS AÑOS 1626 a 1655.}

Fol 460r: «Md. Setiembre 21 1654:/Q. se saquen las pinturas que escogiere Die.o velazqu.z y se lleven $p^{a}$ la sacristia de Sn. Lonrenzo el R1./Fol 461r: He resuelto que las pinturas que se contienen en la memoria que va aquí firmada de Dn Fernando de Fonseca Ruyz de Contreras se saquen de mi Guardajoyas y se entreguen con intervenzión del contralor y Grefier en la forma acostumbrada a Diego Velazquez para que se lleven a la sacristia del Panteon de Sn. Lorenzo el R. Como tengo mandado, Hareis q. Se execute assi./En Md a 21 de Set.re 1654./Al conde de Montalvan./Fol 462v: Memoria de pinturas para la sacristia del Panteon que están en el guardajoyas de S.M.Nelazquez/Lo que Diego Velázquez hallo en la Guaardajoyas de pinturas para la Sacristía del pante6n:/Un tabernáculo de vara $i$ sesma de alto y dos tercias de ancho de evano con sus puertas aforrado por dentro de terciopelo negro con un christo de marfil de media vara de alto./Una adoración de los Reyes en tabla con sus puertas a modo de retablo pintura flamenca con unas letras escritas en las puertas./Otra pintura en la misma forma de retablico sobre tabla pintura flamenca de una anunciata y en las puertas $S$. Fran.co $¥$ S.to Domingo./ (Fol 262r) christo en tabla flama con la Virgen 5 . Ju y la Madalena de tres quaartas de Alto y media vara de ancho./Fm.do don Fer.do de Fonseca Ruiz de Contreras.»

\section{DOCUMENTO V: ARCHIVO HISTÓRICO NACIONAL. SECCIÓN NOBLEZA. TOLEDO. FONDO FRIAS CAJA 229. VOLUMEN DEL AÑO 1660.}

Fol 242r: /«Relazion de las partidas que Don Fran.co Tomás de Villalta Guardajoias de su Mg. A entreg.do con horden del conde de Montalban may. Mas Antiguo de su Mg.d a intervencion de Juøn Lorenço de Cuellar s.rio y contralor y de gaspr de fuensalida grefier y aunque a havido Reales decretos no se lean testado los cargos porque no dicen que se les testen y vajen en virtud del decreto sin otro recado Alguno en esta manera:/[...J/Un tabernaculo por R.l decreto de 21 de Septt.e 1654./A diego Velazquez Aposentador de palacio pa llebar a san Lorenço el Rl $p^{\circ}$ la sacristia nueba del panteon un tabernaculo grande de dos puertas de ebano que tiene dentro un hechura de santo cristo de marfil en la cruz Albibo de mas de una terçia de alto con diadema de lo mismo que la cruz es de ebano con el retulo sobre una tarjeta de marfil forado el tabernaculo en terciopelo negro taaso en duçíentos y cinquenta du.os de v.on. Y la entrego con horden de palabra del sr. Conde de mont.n. Y al marjen de la partida del cargo esta puesto nota del Contralor y Grefier en que lo dicen./Una pintura por dho Rl decreto./Al dho Diego velazquez. $p^{a}$ llebar a sn lorenço el Rl $p^{o}$ la sacristia del panteon una pintura de dos puertas sobre tabla de la Adoracion de los Reyes y en las puertas dos letreros de oro que dicen el misterio con molduras doradas tasado en cuatroçientos rs. Y la entrego con la dha horden y intt.on y la nota del cargo./Un farol Por dho Rl decreto/Al dho Diego Velazquez $p^{a}$ llebar al pardo $p^{a}$ la escalera un farol grande de bidrieras guarneçado de hierro dorado con un floron tasado en quarenta ducados y lo entego con horden del dho s.r conde de doçe de otte de mill y sess. Y cinq.ta y quatro con dha int.on./[...]/Fol 244v: Pide orden para que se le vajen y testen de su cargo a Dn Franc.o tamayo y Villalta todas las partidas contenidas en la relazion inclussa firmada de su mano, por no haverme remitido V.Mg orden para ello./'assi lo he mandado'/'hecho». 